УДК 332.025 .12

\title{
А. Д. Мартынов
}

ЧОУ ВО Московский университет имени С.Ю. Витте, Москва, e-mail: shushol@outlook.com

\section{T. А. Бурцева}

ЧОУ ВО Московский университет имени С.Ю. Витте, Москва, e-mail: burtseva10@mail.ru

\section{ТЕОРЕТИЧЕСКИЕ АСПЕКТЫ ГОСУДАРСТВЕННОГО РЕГУЛИРОВАНИЯ РАЗВИТИЯ АГРОПРОМЫШЛЕННОГО КОМПЛЕКСА}

Ключевые слова: АПК, государственное регулирование, агропромышленный комплекс, оценка эффективности, развитие, метод.

Тема развития народного хозяйства и других сфер агропромышленного комплекса, с учетом имеющегося в Российской Федерации земельного потенциала была всегда актуальной как для советского времени, так и для текущего постсоветского периода становления аграрной экономики Российской Федерации. В данной научной публикации авторы определяют состав агропромышленного комплекса, и указывают на важность его развития для Российской Федерации. Основной темой статьи является рассмотрение государственного регулирования народного хозяйства и сфер АПК как ключевого способа стимулирования роста экономических показателей агропромышленного комплекса и его сфер. В связи с этим, авторы отображают содержание понятия «государственное регулирование развития сфер АПК», выделяют основополагающие принципы государственного регулирования АПК. Формулируют механизм данного подхода, рекомендуют базовые цели гос. регулирования АПК. На основании изучения методов оценки государственного регулирования АПК, в частности «Рекомендации Коллегии Евразийской экономической комиссии от 24.04.2017 №11 О Методологии оценки эффективности мер государственного регулирования агропродовольственного рынка и поддержки агропромышленного комплекса. Приложение: Методология оценки эффективности мер государственного регулирования агропродовольственного рынка и поддержки агропромышленного комплекса» формулируются собственные методы оценки эффективности государственного регулирования развития сельского хозяйства и других сфер АПК.

\section{A. D. Martynov}

Moscow Witte University, Moscow, e-mail: shushol@outlook.com

\section{T. A. Burtseva}

Moscow Witte University, Moscow, e-mail: burtseva10@mail.ru

\section{THEORETICAL ASPECTS OF STATE REGULATION OF THE DEVELOPMENT OF THE AGRO-INDUSTRIAL COMPLEX}

Keywords: Agro-industrial complex, state regulation, agro-industrial complex, efficiency assessment, development, method.

The theme of the development of the national economy and other spheres of agriculture, taking into account the existing in the Russian Federation, the land potential was always relevant to the Soviet era and the current post-Soviet period of formation of the agrarian economy of the Russian Federation. In this scientific publication, the authors determine the composition of the agro-industrial complex, and indicate the importance of its development for the Russian Federation. The main theme of the article is consideration of state regulation of national economy and agriculture as a key method to stimulate economic growth performance of agriculture and its sectors. In this regard, the authors reflect the content of the concept of "state regulation of the development of agricultural sectors", highlight the fundamental principles of state regulation of agriculture. Formulate the mechanism of this approach, recommend the basic goals of state regulation of the agro-industrial complex. Based on the study of methods for assessing state regulation of the agro-industrial complex, in particular " Recommendations Of the Board of the Eurasian economic Commission No. 11 of 24.04.2017 On the Methodology for assessing the effectiveness of state regulation of the agri-food market and support for the agro-industrial complex. Application: the Methodology of evaluation of efficiency of measures of state regulation of agricultural market and support of agriculture» formulated their own methods of evaluating the effectiveness of state regulation of development of agriculture and other sectors of agribusiness. 


\section{Введение}

Благообеспеченность населения напрямую зависит от уровня становления и развития агропромышленного комплекса в целом. На АПК приходится более двух третей всего торгового объема РФ. Он является самым масштабным комплексом страны. Почти четверть основных фондов Российской Федерации и треть национального валового продукта приходятся именно на него.

Три сферы, составляют агропромышленный комплекс:

1) сельское хозяйство

2) производственная (технологическая) его часть;

3) сюда причисляют совокупность отраслей и агропредприятий, целью которых является реализация конечной продукции и предварительная переработка сельхоз-сырья, из которого в последствии получают порядка трех четвертей потребительского товара, за данной сферой также числится хранение и транспортировка.

Главная особенность АПК заключается в его сложном и многообразном строении, которое включает в себя множество отраслей, тесно связанных между собой. Конечная цель комплекса - производство сельскохозяйственной продукции. Агропромышленный комплекс требует немалых вложений: обработка земли - это не только плуг, но и специализированная техника которая поливает, удобряет, собирает урожай - и это только один из многочисленных примеров. Государство имеет все инструменты для того, чтобы влиять на АПК так чтобы это способствовало его развитию.

В этом и заключается роль государства: во влиянии на процессы, связанные с АПК так, чтобы следовать цели создания благоприятных условий для продуктивного взаимодействия всех сфер и отраслей комплекса между собой и наращивания их экономического и производственного потенциала.

Целью исследования является отобразить теоретические аспекты государственного регулирования развития АПК. Ключевыми задачами являются: отобразить содержание понятия «государственное регулирование АПК», отобразить некоторые из проблем на пути государственного регулирования АПК, путем изучения методов оценки эффективности гос. регулирования АПК постараться дать рекомендацию методологии оценки эффективности данного способа влияния на развитие АПК.

\section{Материал и методы исследования}

В рамках проведенного исследования были задействованы следующие материалы: научные публикации по рассматриваемой тематике, экономические книги, электронные ресурсы, рекомендации, нормативноправовые акты. Теоретический и аналитический методы выступили в роли ключевых в рамках научного исследования.

\section{Результаты исследования и их обсуждение}

Гос. регулирование АПК в условиях рыночной экономики является системой определенных мер: исполнительных, контролирующих и правовых. Все они осуществляются для того, чтобы была достигнута стабильность в экономической, социальной и других сферах. Вмешательство государства такого плана в деятельность субъектов хозяйственного характера - это один из ключевых принципов при сегодняшней рыночной структуре агропромышленного комплекса и экономики в целом.

Государственное регулирование является самым эффективном методом воздействия на развитие агропромышленного комплекса, но только при правильном использованном и отточенном механизме предварительного изучения проблематики АПК и применения впоследствии наиболее эффективных методов гос. регулирования.

В рамках развития АПК очень важно не допускать возникновения монополий, которые тормозят развитие АПК из-за падения конкурентоспособности. Пример: в экономике СССР конкуренции не было. Были министерства, которые контролировали все вокруг, а предприятия были направлены на ту или иную сферу деятельности. На сегодня в Российской Федерации все уже по-другому и отношение к монополии не исключение. За контроль возникновения монополий отвечает такой орган государственного надзора как «Федеральная антимонопольная служба РФ». Наиболее характерными и ключевыми его целями являются:

1) Благоприятная конкурентная среда в сферах деятельности хозяйствующих субъектов, не являющихся естественными монополиями;

2) Равный доступ к товарам (работам, услугам) естественных монополий, и развитие конкуренции в потенциально конкурентных видах их деятельности; 
3) Прекращение антиконкурентного вмешательства органов власти в функционирование рынков, высокая эффективность бюджетных расходов при размещении государственного и муниципального заказа [1].

Гос. регулирование экономики и его проблемы изучали такие выдающиеся научные деятели как: Ад. Смит, Дж. Кейнс, Мил. Фридман, Тор. Веблен. Отечественные региональные экономисты также внесли большое вклад в развитие государственного регулирования АПК: П.А. Андреев, Г.А. Баклаженко, А.М. Гатаулин, А.Ф. Серков и многие другие.

Государственное регулирование - система политического, экономического, правового и социального обеспечения благоприятной среды с целью устойчивого развития и адаптации социально-экономической системы и отдельных ее субъектов к изменяющимся экономическим условиям [2].

Государство должно регулировать процесс структурной перестройки экономики в соответствии с главной целью рыночных отношений - социологизацией, повышением материального благосостояния населения [3].

Принципами государственного регулирования являются:

1) задействование экономических методов влияния;

2) отсутствие возможности прямого вторжения в деятельность предприятий АПК;

3) использование программ в качестве методов развития;

4) прямая финансовая поддержка за счет финансово-кредитной политики что является базовой концепцией гос. регулирования АПК;

5) соблюдение соотношения уровня цен и доходов населения;

6) возможность использования денежного механизма (налоги, таможенные пошлины), льготные условия на предпринимательство;

7) создание спроса на сельхозпродукцию.

Касательно последнего пункта стоит заострить внимание на том, что государство способно устанавливать международные партнерские отношения и повышать спрос на сельскохозяйственную за рубежом. Интерес государства заключается в получении прибыли. Для этого необходимо наращивать продуктивные партнерские отношения между агропредприятиями и государством.
Механизм государственного регулирования АПК состоит из: нормативного, социального финансового и экологического регулирования.

1) к правовому регулированию относят создание нормативно-правовой базы, техническую регламентацию, ветеринарные/ санитарные и схожие меры;

2) социальное регулирование также необходимо и призвано решать социальные вопросы, предоставлять защищенность гражданам и лицам трудящимся на благо АПК, обеспечивать их занятостью, правами, устанавливать нормы качества и условия труда, которые обязан предоставить работодатель в соответствии с данным регулированием;

3) финансовое регулирование является ключевым относительно вопроса понятия экономического воздействия государства на АПК. Сюда относят инвестиционную деятельность, денежно-кредитную политику, регулирование ценовой политики, пошлины и многое другое носящее схожий характер воздействия

В целом же экономическая сущность государственного регулирования, заключается в воздействии государства на экономические процессы и людей, затронутых в рамках рыночных взаимоотношений так чтобы повышать организованность процессов, предоставлять законодательную базу для экономической защищенности населения, и основу для достижения целей общества и государства.

Оптимальным случаем государственного регулирования экономической системы АПК является создание успешного баланса свободы действий на экономическом рынке и регулирования побочных процессов. Разрабатываются программные стратегии развития, преследующие цель повышения уровня жизни населения и уверенности в завтрашнем дне и контроле развития возможностей и свободы в рамках деятельности на рыночной экономике.

Исходя из этого можно заключить что государственное регулирование агропромышленного комплекса должно ставить перед собой 3 ключевые цели:

1) создание благоприятных и стабильных условий для агропредприятий с целью повышения их продуктивности и ускорения темпов роста качества и объемов производства;

2) развитие сельского хозяйства и поднятие уровня жизни населении;

3) развитие правовой системы защиты агропредпринимателей. 
Касательного государственного регулирования АПК И.В. Панова, Е.А. Городецкая в своем исследовании считают необходимым принятие комплексного закона о регулировании деятельности в сфере агропромышленного комплекса и определение в нем понятия агропромышленного комплекса, перечня видов государственной поддержки, форм и методов регулирования АПК, их основной концепции, но ни в коей мере не конкретных объемов поддержки и круга ее субъектов в тех случаях, когда такой круг не является константой. Данный закон, по их мнению, составил бы базу законодательства о государственном регулировании аграрных отношений [4]. Авторы согласны с тем что необходимо развивать законодательную основу и закреплять основные положения государственного регулирования, что создало бы понятный механизм использования определенных мер по поддержке АПК и структуру принятия решений, а также бы закрепило основные положения гос. регулирования комплекса и предоставило бы правовую защищенность агропредприятиям что соответствует третьей цели государственного регулирования АПК которую выделяют авторы. Однако стоит отметить, что нельзя законодательно ограничивать виды государственной поддержки, т.к. порой они нуждаются в развитии и дополнении в связи с появлением новых актуальный тенденций и направлений по поддержке государством агропромышленного комплекса и возникновения нестандартных ситуаций. Меры поддержки должны быть разделены и закреплены как «основные» с пояснением и указанием и дополнительные.

При государственном регулировании АПК может возникать множество проблем, одна из них связана с большим количество отраслей, которые присутствуют в АПК, ситуация в одних способна влиять на другие, а ставка в регулировании на одну сферу и развитие ее отраслей может повлечь за собой упущение нити в развитии и устранении проблематики в другой. Многообразность АПК выходит здесь в некотором смысле боком.

Второй проблемой государственного регулирования является необходимость постоянного контроля цен на сельскохозяйственную продукцию.

Третьей проблемой государственного регулирования является методология выстраивания государственного регулирова- ния и оценки эффективности влияния государства на АПК. На этом авторы предлагают сделать ставку.

Для того чтобы оценить эффективность государственного регулирования АПК необходима методология оценки действий, которые предпринимаются государством в этом направлении.

Булгакова Л.Н. и Абубакаров М.В. в своем исследовании методов оценки эффективности разработали собственную методику оценки эффективности государственного регулирования агропредприятий и вывели свой показатель эффективности государственного регулирования $Э_{\text {perं }}$

Они выделяют пять этапов оценки государственного регулирования:

1) определение эффективности государственного регулирования каждого агропредприятия входящего в отрасль региона

2) определение показателя предельной эффективности хозяйствующего субъекта за 3 года с гос. поддержкой и без нее

3) расчет показателя эффективности государственных мер поддержки

4) оценка эффективности реализации по всей отрасли

5) использование метода имитационного моделирования для оценки влияния всех мероприятий государственного регулирования [5].

Данная система методологии оценки является довольно точечной, но при этом масштабной, т.к. необходимо задействовать множество ресурсов чтобы оценить каждую отрасль и каждое предприятие в нем. Также она, как и следующая методология изучает только то, что было сделано и какой из этого вышел результат. На сегодня для РФ самой глобальной методологией оценки эффективности, заслуживающей наибольшего внимания, является Рекомендация Коллегии Евразийской экономической комиссии, а именно Приложение. «Методология оценки эффективности мер государственного регулирования агропродовольственного рынка и поддержки агропромышленного комплекса».

В рамках данного Приложения выделяется два основных этапа оценки эффективности. На первом этапе по данной методологии идет оценка решений, принятых государством, в зависимости от используемых методов государственного регулирования в стране и поставленных целей которые разделяют на 3 группы: типовые, компле- 
ментарные и индивидуальные. Ключевым показателем эффективности считается достижение лей. На втором этапе приводятся примеры типовых целей и рассматриваются критерии которые определяют понятие достижения целей АПК которое как уже было сказано по данному Приложению к Методологии является ключевым.

Систематизировав, получаем следующие критерии:

1) оценка объема достижения целей и решения задач;

2) оптимальность использования ресурсов и своевременность достижения результатов;

3) оценка положительных и отрицательных результатов после принятых мер;

4) устойчивость принятых мер;

5) затратность: соотношение отдачи к издержкам [6].

По каждому критерию необходимо провести оценку факторов, которые на них влияют. После этого проводится оценка статистических показателей каждого критерия в динамике и высчитывается итоговая оценка по каждому критерию что приводит к итоговой оценке эффективности государственного регулирования АПК покритериально.

В рамках исследования данного Приложения к методологии, авторы отмечают большое упущение не включения сюда следующих подходов к оценке эффективности гос. регулирования АПК:

1) Первое и самое важное - первоначально должна быть проведена подробная посферная оценка проблематики агропромышленного комплекса, только после этого государство может проводить политику влияния на АПК.

2) В соответствии с изучением проблематики АПК должны быть поставлены цели и задачи, которые обязаны носить актуальный характер исходя из пункта 1 и которые способствовали бы истреблению ключевых проблем, наиболее мешающих развитию комплекса в определенный период в той или иной его сфере.

3) Только после этого исходя из проблематики применяются, дополняются методы государственного регулирования АПК, эффективность действий которых будет оценена в последствии.

Авторы отмечают, важность понимания сути, что достижение цели исходя из практикующихся методов государственного ре- гулирования в стране с последующей покритериальной оценкой может оказаться не глобальным для развития АПК и не истреблять его главные проблемы на текущем этапе развития или даже решение одних проблем может усугублять другие без предварительного изучения состояния комплекса и процессов, тесно связанных с ним. В данной методологии:

1) Не отображается актуальность постановленных целей и важность целенаправленного изучения проблематики АПК чтобы дать оценку уровню важности решаемым задачам.

2) Не изучается влияние достижения цели и использованных методов на другие процессы, связанные с АПК.

3) Не делается ставка на то, что не цели ставятся исходя из практикующихся методов, а методы должны модернизироваться под поставленные цели.

Рекомендация авторов по методологии оценки эффективности государственного регулирования АПК заключается в следующем. Оценка эффективности должна проходить в 3 этапа:

1) Оценка актуальности поставленных целей исходя из посферных проблем АПК, которые ставились и решались в ходе вмешательства государства.

Сюда стоит отнести:

А) Изучение ключевых проблем агропромышленного комплекса и рынка сельскохозяйственной продукции РФ на момент постановки цели.

Б) Путем сравнения проводится оценка актуальности цели, которая была поставлена государством, и решалась в ходе определенного периода, и которая вытекала исходя из оценки проблематики АПК присущей в тот период.

Балльная система оценки:

-1 - в сфере комплекса имелись весомые проблемы, государство положительного влияния не оказало;

0 - проблемы сферы комплекса решались, но не ключевые;

1 - решалась ключевая проблема сферы АПК.

2) Оценка итогов: достижение $\backslash$ не достижение цели как результат, уровень качества задействования и соответствия метода государственного регулирования АПК поставленной цели.

А) Установление факта достижения । не достижения цели. 
Балльная система оценки:

-1 - поставленная цель не была достигнута;

0 - поставленная цель достигнута, но не полностью или решены не все задачи;

1 - поставленная цель достигнута.

Б) Каждому методу государственного регулирования присущи свои критерии оценки и факторы, которые на них влияют, необходимо произвести оценку эффективности задействованных методов государственного регулирования и изучить его критерии и факторы, которые повлияли на него.

3) Оценка влияния итогов на другие процессы, связанные с АПК.

Необходимо произвести оценку того, как действия предпринятые в рамках достижения этой цели повлияли на другие процессы, связанные с АПК.

Балльная система оценка:

-1 - отрицательное влияние;

0 - нейтральное влияние;

1 - положительное влияние.

Итоговая оценка эффективности государственного регулирования АПК выставляется путем сложения первых трех величин:

3 - максимальный уровень эффективности государственного регулирования сферы АПК;

2 - хороший уровень эффективности государственного регулирования сферы АПК;

1,0 - удовлетворительный уровень влияния на сферу АПК если ни на одном из этапов не присутствовала оценка -1 ;
$-1,-2,-3$ - три уровня негативного и неэффективного влияния государства на процессы, связанные с АПК.

Повышение уровня эффективности гос. регулирования развития АПК и недопущение некачественного государственного регулирования АПК в рамках которого решаются только второстепенные или неактуальные для комплекса задачи, возможно в первую очередь за счет реализации качественного анализа состояния АПК и изменения подхода к методологии оценки эффективности гос. регулирования, это возможно решить за счет:

1) создание «Департамента выявления проблематики АПК и сельскохозяйственной продукции» в разрезе «Министерства Сельского Хозяйства РФ»;

2) создание «Профсоюза предпринимателей агропромышленного комплекса»;

3) проведение работ НИИ в этом направлении;

4) проведение научно-исследовательских работ региональными экономистами по данному направлению.

\section{Заключение}

В рамках исследования были рассмотрены теоретические аспекты государственного регулирования АПК, его основополагающие цели, принципы, методы влияния на АПК. Было проведено исследование методологий по оценке эффективности гос. регулирования АПК. Итогом исследования стали рекомендации авторов по методам оценки эффективности данного способа воздействия на АПК.

\section{Библиографический список}

1. «ФАС России | Миссия, цели, ценности» [Электронный ресурс]. https://fas.gov.ru/pages/about/ mission.html.

2. Агарков А.П., Голов Р.С., Теплышев В.Ю., Ерохина Е.А. Экономика и управление на предприятии. М.: ИТК «Дашков и К», 2013. 400 с.

3. Государственное регулирование экономики: учеб. пособие для вузов / под ред. проф. Т.Г. Морозовой. М.: ЮНИТИДАНА, 2002. 255 с.

4. Панова И.В., Городецкая Е.А. Агропромышленному комплексу необходимо новое законодательное обеспечение // Право. Журнал Высшей школы экономики. 2013. январь-март. №1.

5. Булгакова Л.Н., Абубакаров М.В. Методы оценки эффективности государственных мер поддержки и регулирования сельскохозяйственного производства // Экономический вестник Ростовского государственного университета. 2008. Том 6. №2. Ч. 2.

6. Рекомендация Коллегии Евразийской экономической комиссии от 24.04.2017 № 11 «О Методологии оценки эффективности мер государственного регулирования агропродовольственного рынка и поддержки агропромышленного комплекса» Приложение. «Методология оценки эффективности мер государственного регулирования агропродовольственного рынка и поддержки агропромышленного комплекса». 